\title{
O Ensaio Clínico COURAGE: Visão de um Cardiologista Clínico
}

\author{
Gilson Feitosa ${ }^{1}$
}

A escalada do aproveitamento efetivo do conhecimento científico na área cardiológica se faz às custas de degraus cada vez mais delgados, considerando-se as ferramentas atualmente disponíveis.

Saltos substantivos raramente são observados em trajetórias recentes.

O tamanho do benefício advindo de novas estratégias terapêuticas em acréscimo ao que já se encontrava assentado, ultimamente, tem sido de pequena magnitude. $\mathrm{O}$ que em nada diminui ou faz esmorecer os gigantes que impulsionam esses avanços.

Faz-se mais difícil a luta, porém surgem as oportunidades para o melhor tirocínio, o melhor aproveitamento e a otimização do uso dos recursos, tudo com um só fito, que é a promoção do bem estar e da longevidade dos pacientes acometidos por doença cardiovascular, o que tem sido observado de forma consistente.

Por sua alta prevalência, impacto na morbidade e mortalidade das diferentes populações do globo e por seu resultante significado econômico, a doença arterial coronária tem sido alvo de intensa investigação quanto aos seus complexos mecanismos e tratamento.

A conseqüência fundamental de sua presença é o insuficiente fornecimento de fluxo sanguíneo a suprir as necessidades de oxigênio do miocárdio dependente de sua irrigação.

Tal fenômeno, a isquemia miocárdica, é a essência do desenvolvimento de todas as manifestações clínicas e complicações cardíacas da doença, a saber: a angina do peito, o infarto do miocárdio, a insuficiência cardíaca e a morte súbita.

Na quase totalidade dos casos, em se tratando de aterosclerose coronária, há uma reconhecida linha direta de fatos que correlacionam oclusões totais ou estreitamento significativo de artérias coronárias em seu segmento epicárdico, geralmente maior que 50 ou $70 \%$, e a determinação de isquemia miocárdica.

Outros mecanismos, como espasmos coronários e falta de dilatação arteriolar, são muito menos freqüentes e relevantes no contexto.

A capacidade de prover fluxo com enxertos cirúrgicos ou a restauração da luz dos vasos com intervenção percutânea oferece, assim, uma atraente perspectiva de atuar na solução do problema, desde que exeqüível e sem agravos intensos ou duradouros ao bem estar do paciente.

Tais intervenções trazem comprovados benefícios a um considerável número de pacientes.

É este o caso nas síndromes coronárias agudas, que representam a maioria dos pacientes tratados por tais recursos ${ }^{1}$ ou em um grupo de pacientes que têm isquemia como substrato para importante disfunção ventricular, ou ainda aqueles que têm intensa isquemia miocárdica revelada por sintomas ou em testes de avaliação.

Tal constatação, naturalmente, forma uma conexão com a idéia de que o princípio do alívio mecânico da doença arterial coronária possa se estender além das situações clínicas acima delineadas.

Por enquanto, com os recursos atualmente disponíveis, estamos distantes de uma atitude tão abrangente de indicação desses procedimentos, sem uma considerável análise caso a caso da vantagem do seu emprego.

Na realidade, essa percepção já permeava francamente o entendimento de cardiologistas clínicos, intervencionistas ${ }^{2}$ e cirurgiões, que já a expressavam em

\footnotetext{
1 Escola Bahiana de Medicina e Saúde Pública, Hospital Santa Izabel, Santa Casa de Misericórdia da Bahia, Salvador, BA. Correspondência: Dr. Gilson Feitosa. Rua Florida 211/302 - Salvador - BA - CEP 40150-480 - E-mail: gfeitosa@cardiol.br Recebido em: 20/08/2007 • Aceito em: 27/08/2007
} 
suas respectivas diretrizes, com exigências bem demarcadas na indicação classe I para procedimentos de revascularização.

O estudo COURAGE (Optimal Medical Therapy with or without PCI for Stable Coronary Disease $)^{3}$ deu um passo a mais confirmatório dessa impressão. Os autores compararam de maneira prospectiva, controlada e randomizada, em pacientes selecionados portadores de doença arterial coronária estável, uma estratégia de tratamento baseada em intensa aplicação de recursos medicamentosos e higieno-dietéticos, com a mesma estratégia acrescida de intervenção percutânea.

Obviamente, os pacientes escolhidos por critérios clínicos e cinecoronariográficos teriam que apresentar lesões coronárias passíveis de tratamento por intervenção.

Estas e outras razões excluíram 33.252 pacientes dos 35.539 considerados inicialmente para o estudo, portanto, apenas $6,4 \%$ dos mesmos foram avaliados.

Tal fato tem sido repetidamente visto em ensaios clínicos comparativos dessa natureza e, conquanto não desmereça a importância do estudo, serve de alerta para que se esteja atento após as suas conclusões e a quem de fato elas se aplicam.

Foram excluídos do estudo 6.554 pacientes, por razões logísticas, e 1.071, o foram por falha medicamentosa.

Em outras palavras, um número considerável de pacientes não fariam, com a aderência necessária, o tratamento clínico medicamentoso ou, ao tentá-lo, o fizeram mal, razão porque não foram incluídos no estudo.

Depreende-se que os resultados do COURAGE são aplicáveis a pacientes com as características selecionadas e com garantida utilização, com grande aderência, dos recursos clínicos oferecidos.

É lícito questionar-se se seriam os resultados os mesmos em casos de menor aderência aos medicamentos.

Considerando-se os pressupostos já mencionados, verifica-se um estudo bem delineado, bem conduzido, que oferece algumas respostas e deixa em aberto alguns questionamentos, além do acima exposto.

Uma das suas constatações mais relevantes é a de que é possível implementar de verdade, embora que no mundo de um ensaio clínico, recomendações emanadas de diretrizes, com bom êxito.

Este foi o caso do uso dos medicamentos e do alcance de metas lipídicas.

Menor sucesso foi observado na implementação da mudança de hábitos, como: o estímulo à prática do exercício, que ao final do estudo somente era realizado de forma moderada em 42 e 36\% dos pacientes; da abolição do tabagismo, que ainda permanecia em
17 e 20\%; e, da redução do peso, que não se modificou durante o tratamento, apresentando um IMC de 29 e 29,5 $\left(\mathrm{kg} / \mathrm{m}^{2}\right)$, respectivamente, no grupo clínico intensivo e no grupo clínico intensivo + revascularização percutânea. De qualquer forma, um reforço à idéia de que é possível garantir um tratamento desse tipo.

Em assim procedendo, em pacientes com apreciável demonstração de isquemia, angina e com quadro clínico fora do conceito de instabilidade clínica, os resultados em 4,6 anos foram muito semelhantes entre as duas estratégias em relação aos desfechos relevantes de infarto e morte por qualquer causa. Desfechos esses que foram adjudicados de maneira cega.

Embora o estado anginoso fosse de início favorecido por uma estratégia de revascularização, ao final do estudo, era semelhante ao do tratamento clínico, embora que para que tal ocorresse um número significativamente maior de intervenções percutâneas fossem realizadas nesse grupo, transmitindo-nos a idéia de que 1/3 dos pacientes em tratamento clínico necessitarão, por conta de sintomas, desse tratamento complementar.

Alguns têm apresentado argumentações de que o procedimento intervencionista, neste estudo, talvez não tivesse sido realizado nas melhores condições da atualidade. Apontando-se como indicativos disso um emprego exclusivo de balão em 14,5\% dos casos, algum grau de revascularização incompleta pela desproporção entre lesões multivasculares e o emprego de apenas um stent, pequeno uso de IGPIIb/IIIa, falta de uso de stents com eluição de medicamentos e sucesso primário angiográfico da intervenção de 93\%.

Uma contra-argumentação apresentada é a de que o que se viu no estudo está em conformidade com a melhor prática atual, e que a desproporção de stents nos multivasculares se devia a cirurgias de revascularização ou infartos prévios.

No momento, somam-se as evidências de que importantes problemas podem advir de lesões não necessariamente expressivas por seu comprometimento da luz vascular e que, ainda assim, podem eventualmente se romper e gerar fenômenos oclusivos agudos com suas conseqüências.

O relativamente eficaz tratamento estabilizador de placas com a medida de intensa redução do C-LDL, como se pode fazer hoje em dia, tem um alcance amplo.

É provável que desenvolvimentos futuros tornem a expectativa de um tratamento intervencionista mais abrangente uma realidade. Alguns passos deverão ser seguidos para atingir esse fim.

A identificação não-invasiva de lesões com potencial evolutivo, obstrutivas ou não, é um desses passos, permitindo um conveniente planejamento do procedimento.

A atuação sobre lesões ateroscleróticas coronárias, sem reestenose das obstruções mais significativas e, selamento das demais, com procedimentos a um só 
tempo eficazes e de baixo custo, será um outro. O continuado esforço científico e tecnológico haverá de nos levar nessa direção.

Até que isso ocorra, estudos como o COURAGE deverão ser a base para decisões que individualizem em doença arterial coronária estável os procedimentos em cada caso, levando-se em conta as características clínicas, angiográficas e da qualidade local do tratamento oferecido, com participação mais efetiva do paciente bem esclarecido sobre as reais perspectivas, do cardiologista clínico bem informado e do cardiologista intervencionista.

\section{REFERÊNCIAS BIBLIOGRÁFICAS}

1. Feldman $\mathrm{DN}$, Gade $\mathrm{CL}$, Slotwiner $\mathrm{AJ}$, Parikh $\mathrm{M}$, Bergman G, Wong SC, et al. Comparison of outcomes of percutaneous coronary interventions in patients of three age groups $(<60$ 60 to 80 , and $>80$ years) (from the New York State Angioplasty Registry). Am J Cardiol. 2006;98(10):1334-9.

2. ACC/AHA/SCAI 2005 Guideline update for percutaneous coronary intervention. Disponível em: www.scai.org

3. Boden WE, O'Rourke RA, Teo KK, Hartigan PM, Maron DJ, Kostuk WJ, et al. Optimal medical therapy with or without PCI for stable coronary disease. N Engl J Med. 2007;356(15): 1503-16. 